\title{
El marxismo, la totalidad y su devenir histórico
}

\author{
Marxism, totality and its historical beginnings
}

\section{Olga PÉREZ SOTO* Arelys ESQUENAZI BORREGO**}

\begin{abstract}
Resumen: Este artículo se propone reflexionar sobre la importancia de pensar la sociedad desde el marxismo como paradigma de ciencia y la totalidad como uno de sus fundamentos. Rescatar en su obra cumbre El Capital, el análisis del marxismo como la integración de sus partes y fuentes, es una necesidad en la contemporaneidad en la suscripción como ideología y teoría para la transformación social como ruptura y superación del capitalismo imperialista. Para ello, el artículo comienza por abordar la totalidad dentro del marxismo y su desarrollo en la tradición marxista; luego analiza el marxismo como paradigma de ciencia y la totalidad como fundamento del mismo; y finalmente, se debate la totalidad en el análisis del capitalismo y del socialismo.

Palabras clave:Marxismo. Totalidad. Vigencia. Transformación social.
\end{abstract}

\begin{abstract}
This article reflects on the importance, as one of its foundations, of Marxist thinking about society as a paradigm of science and totality. Reclaimed in his work Capital, the analysis of Marxism as the integration of its parts and sources, is a need, in the contemporary, for the subscription to an ideology and theory for social transformation as a break with, and overcoming of, imperialist capitalism. The article begins by addressing totality within Marxism and its development in the Marxist tradition; it then analyses Marxism as a paradigm of science and totality as one of its foundations; and finally, totality is debated in the analysis of capitalism and socialism.
\end{abstract}

Keywords: Marxism. Totality. Validity. Social transformation.

Submetido em: 12/4/2018. Revisado em: 4/7/2018. Aceito em: 21/8/2018.

\section{INTRODUCCIÓN}

$\mathrm{E}$ xplícita e implícitamente, el debate sobre marxismo, es el debate sobre las alternativas, es el debate sobre el cambio social. Cada convocatoria para pensar en Marx -ya sea por aniversarios de natalicio, de fallecimiento, o años de publicación de su obra cimera El Capital- son expresiones en todos los tiempos del reconocimiento de la vigencia de su pensamiento; así como, de la necesidad y urgencia de la emancipación social. Es natural que sea así; pues el marxismo como paradigma de ciencia, significó y significa una ruptura metodológica y epistemológica con el resto de los paradigmas de pensamiento de la realidad; identificando un objeto y con un método para discernir entre esencia y apariencia de los fenómenos. Adicionalmente, el marxismo como ciencia e ideología no está enfocado

\footnotetext{
*Doctora en Economía por la Universidad Autónoma de Barcelona. Profesora Titular de la Universidad de La Habana. Calle L\# 353 e/ 23 y 25, La Habana, Cuba. Profesora visitante extranjera en el Programa de Post Graduación en Política Social, Universidad Federal de Espírito Santo (Vitória (ES), Brasil). E-mail: <perezolgasoto@yahoo.es>. ORC ID: <http://orcid.org/oooo-0oo2-1542-7678>.

${ }^{* *}$ Máster en Economía por la Universidad de La Habana. Doctoranda en el programa de Post-graduación en Política Social de la Universidad Federal de Espírito Santo. Bolsista CAPES. E-mail: <arelyseb@gmail.com>. ORC ID: <http://orcid.org/oooo-0002-9366-8688>.
} 
simplemente a la interpretación y crítica de la realidad; sino esencialmente a su transformación revolucionaria.

Este artículo se suma a la convocatoria de la revista Argumentum y tiene como motivación, reflexionar sobre los desafíos que supone, para todas las personas progresistas y comprometidas con la transformación social a nivel mundial, la conmemoración del 135 aniversario del legado de Marx. Continuar apostando por la actualidad, pertinencia, vigencia e importancia de la crítica del marxismo como arma analítica en la contemporaneidad, contribuye al continuo desarrollo del pensamiento marxista; y, como consecuencia, a la alternativa posible y necesaria, por ruptura y superación del capitalismo imperialista contemporáneo.

El objetivo de este artículo es reflexionar sobre la importancia de pensar la sociedad con un enfoque de totalidad; utilizando el marxismo como paradigma de ciencia y herramienta analítica. Rescatar en el pensamiento marxista en general, y en particular en su obra cumbre $E l$ Capital, el análisis del marxismo como la integración de sus partes y fuentes, es una necesidad en la contemporaneidad para su suscripción como ideología y teoría para la transformación social contemporánea.

El artículo está estructurado en tres partes relacionadas. Primero se aborda la totalidad dentro del marxismo y su desarrollo en la tradición marxista; luego se analiza el marxismo como paradigma de ciencia y la totalidad como fundamento del mismo. Finalmente, se debate la totalidad como base del análisis del capitalismo y del socialismo.

\section{LA TOTALIDAD EN EL DESARROLLO DEL MARXISMO}

Estas autoras en otros artículos, se han posicionado en el debate entre el marxismo y los marxismos; asumiendo que el marxismo es un paradigma de ciencia que propone un método para interpretar la realidad y transformarla subvirtiéndola. En él conviven distintas corrientes que comparten sus fundamentos analíticos, sin tener que coincidir necesariamente en todos los enfoques y propuestas. De otra manera, el marxismo no sería un organismo vivo en constante desarrollo.

En otras palabras, consideramos oportuno para los objetivos de este trabajo comenzar por subrayar que la totalidad del marxismo como paradigma (o el fundamento de totalidad del paradigma marxista), parte de la comprensión del marxismo y no de los marxismos. El marxismo como paradigma de ciencia contiene la diversidad de la tradición marxista, sus corrientes y autores articulados en una comunidad científica plural unida por el objeto, el método y los fundamentos del marxismo. La heterogeneidad de la tradición marxista la desarrolla y fortalece. La totalidad del marxismo, entendida como algo más que sistema e interrelaciones, asume la diversidad de enfoques a partir de la crítica como herramienta de conocimiento científico.

La totalidad del marxismo concretada en la comunidad científica de su tradición es uno de los temas más difíciles de enfrentar en la cotidianidad. El marxismo, en muchas ocasiones, es abrazado intuitivamente por personas, movimientos sociales, sindicatos, partidos, etc.; con un mayor o menor grado de conocimiento del mismo. Lo hacen desde el entendido de suscribir que es una teoría para la emancipación social. Lo anterior no sería problema si esa

Argum., Vitória, v. 10, n. 2, p. 43-55, maio./ago. 2018. 
suscripción instintiva provocara necesidad de conocimiento y debate desde sus fundamentos.

Al mismo tiempo, es utilizado por académicos, cientistas sociales y políticos que lo suscriben conociéndolo y habiéndolo estudiado. Este grupo se desdobla en varias modalidades. Los que lo estudian y estudiaron pero no logran aplicar ni ver el alcance de todos sus fundamentos; los que lograron entenderlo estudiándolo pero que no logran ser consecuentes en su aplicación a la práctica social y terminan atrapados en el dilema de que la práctica no cabe en la teoría o esta no cabe en la práctica; y por último, los que lo abrazan, lo suscriben de palabra pero no hecho, ni en teoría, ni en práctica, pero que por alguna extraña razón necesitan denominarse marxistas. Asumir los marxismos como expresión y/o reconocimiento de pluralidad en su interior, es fragmentar al paradigma marxista como ciencia de la totalidad.

La cuestión anterior se manifiesta muchas veces en los mismos proyectos investigativos, no solo marxistas sino y también dentro de las ciencias sociales en general. Muchas veces desde motivaciones legítimas y auténticas se abordan proyectos de investigación de partes de la realidad en cualquiera de los grupos arriba mencionados, y en la identificación del objeto de la misma, se ignora el lugar del objeto en la totalidad; y como consecuencia, se omite la utilización del método en su aplicación concreta a dicho objeto, alejándose de lo que para el marxismo es la base de la producción de conocimiento científico.

Como si fuera poco, en los procesos de formación profesional, en la mayoría de los casos, se parcela el conocimiento del marxismo como paradigma de ciencia, en disciplinas y/o asignaturas (sin interrelación alguna, sin vínculo con las especialidades estudiadas, ni con la realidad) con una mezcla de vulgarización y parodia de mal gusto en relación a la totalidad del marxismo. El tema en cuestión se complejiza cuando se le añade a este proceso, que esas parcelas son por si solas el marxismo. Se produce un proceso de caricatura del marxismo en los procesos de formación, reduciendo el todo a algunas de las partes; privilegiando o ignorando el resto del paradigma en su totalidad. El resultado en el mejor de los casos es que los egresados profieren algunos elementos del marxismo como etiqueta o catecismo incapaz de encontrar vínculo con la sociedad como un todo.

Relacionado con lo anterior también vale mencionar, por su importancia, la derivación de lo arriba expuesto en los procesos de difusión del marxismo como parte de la formación de la conciencia social y política de las masas; que bajo el genuino reconocimiento de que el marxismo es la ideología para la transformación social, se ha propagado la parcelación del marxismo a partir de áreas y temáticas inconexas para facilitar su compresión, divorciando las partes sin garantizar un lugar de encuentro común al pensar la sociedad .

\section{LA TOTALIDAD DEL MARXISMO COMO PARADIGMA DE CIENCIA}

\section{1) Fuentes y partes componentes del marxismo}

Comencemos por recordar que el pensamiento revolucionario contemporáneo a través del marxismo es el resultado de las condiciones históricas y sus componentes teóricos. En el primer caso nos referimos a las transformaciones iniciadas en Europa Occidental en los siglos XV y XVI con la llamada "revolución comercial”, y que llegan hasta los siglos del XVIII al XIX, resumidos en aquellos tres grandes procesos explicados por Marx como: Cooperación

Argum., Vitória, v. 10, n. 2, p. 43-55, maio./ago. 2018. 
Simple, la Manufactura y la Gran Industria, también denominada como "revolución industrial”. En resumen, se está haciendo referencia a todo el proceso de consolidación del capitalismo industrial naciente, clásico, liberal o de libre concurrencia o competencia.

Todas las transformaciones económicas, sociales y políticas aparejadas al surgimiento del capitalismo industrial, fueron consideradas como progreso, resultado de la revolución que representaba la burguesía, tipificada a través de la Revolución Francesa. El surgimiento de la sociedad burguesa nace con una "igualdad formal" y "legal" entre los hombres a partir de solapar la desigualdad esencial y real expresada entre los poseedores de medios de producción y los poseedores de fuerza de trabajo.

La sociedad capitalista de mediados del siglo XIX ya estaba consolidada y desde sus inicios, contenía las contradicciones, antagonismos y crisis acompañadas con formas y expresiones de rechazo por las masas trabajadoras. Es por eso que la sociedad burguesa con sus injusticias y las contradicciones sociales que genera desde su interior, fue y continua siendo un terreno fértil de creación de pensamiento revolucionario y transformador.

Este breve relato busca significar que el pensamiento no nace del vacío. Las aportaciones de Marx surgen en esta compleja realidad y se encuentran signadas por dicho contexto sociohistórico, y por los principales avances de la ciencia hasta ese momento. En la formación del pensamiento de Marx se reconocen tres fuentes y partes componentes fundamentales.

Las fuentes reconocidas son: con la filosofía clásica alemana, la economía política inglesa y el socialismo utópico francés. En la primera, los filósofos alemanes Feuerbach y Hegel, especialmente Hegel que analizó la realidad como proceso dialéctico dinámico y contradictorio; en la segunda, Adam Smith y David Ricardo economistas políticos ingleses, aportaron que la riqueza producida por los hombres es resultado de su trabajo, al analizar este como creador de valores económicos; y la tercera, los pensadores franceses, Saint-Simon, R. Owen y Fourier, criticaron la irracionalidad de sociedad burguesa. De las bases de estas investigaciones de la sociedad burguesa nace una genuina revolución teórica que es el marxismo como paradigma; que elabora un modo nuevo de conocer la historia, la sociedad, la cultura y de producir conocimiento para interpretar y trasformar la realidad. En síntesis, una ruptura epistemológica con todas las propuestas anteriores.

Los componentes de esta propuesta inicial la realiza Carlos Marx, con las contribuciones y apoyo de Federico Engels y otros valiosos seguidores, y es conocida como el marxismo originario. Sus principales componentes son reconocidos como: la filosofía marxista, la economía política marxista y el comunismo científico. Esta propuesta de paradigma de ciencia contiene el núcleo del pensamiento revolucionario y el análisis de la crítica a la sociedad burguesa; planteando que los intereses de las clases que representan ese orden burgués capitalista son irreconciliables por representar al capital y al trabajo, y que se expresan políticamente en la lucha de clases y en profundas contradicciones de las relaciones sociales de producción y de las fuerzas productivas que la acompañan; constituyéndose en medio para el fin de la valorización como expresión de la acumulación de capital como proceso ininterrumpido que necesita de las crisis como parte necesaria de funcionamiento del sistema capitalista. 
Ese núcleo duro se desarrolla con una propuesta de método de conocimiento de la realidad, con el que se llega a la Ley de la plusvalía como Ley Económica Fundamental de la producción capitalista (como desarrollo de la Ley del valor); la cual en su desarrollo se transforma en Ley de la acumulación capitalista (reinversión de plusvalía en capital). Lo anterior deriva en el análisis del capital como una relación social de producción, que contiene relaciones de clases sociales y de toda la superestructura de la sociedad burguesa.

Lo que hemos comentado hasta acá ha sido con la intención de rescatar en una apretada síntesis, cómo el paradigma marxista es una propuesta integrada desde la totalidad entre análisis filosófico (dialéctico y materialista); análisis desde la economía política (la creación de la riqueza social por el capital como relación social de producción capitalista), y el comunismo científico (como el reflejo de la contradicciones entre las clases sociales y la necesidad de cambio social por oposición y superación de la lógica del capital). De forma aislada los componentes del marxismo (solamente la dialéctica o la economía política o el imaginario social alternativo), no hubieran permitido a Marx proponer una teoría científica para la lucha de clases. Solo la aplicación del fundamento de totalidad del análisis marxista sirvió para demostrar la esencia de la sociedad capitalista como sociedad explotadora del hombre y, por ende, la necesidad de emancipación social.

2.2) El marxismo como filosofía, economía política y comunismo: la obra "El Capital"

Cuando se debate del marxismo es muy curioso identificar como es frecuente en las polémicas, incluso al interior del paradigma, las diferentes entradas y defensas no integradas de las distintas partes del mismo; así como, la ausencia de un enfoque de totalidad, por lo que en muchas ocasiones se defiende la desfragmentación, las partes desarticuladas y no la totalidad del paradigma.

En esta parte del artículo se analizan las partes integrantes a través de la obra de Carlos Marx: "El Capital". Para ello se aborda la obra como totalidad, a través de la selección de ideas que, aunque no agotan el tema, son elocuentes a 135 años del legado de Marx, para rescatar la importancia del enfoque marxista de la totalidad en los análisis contemporáneos. Los dos aspectos seleccionados son: el método marxista y la relación entre Economía Política y Economía.

\subsection{1) Método marxista como expresión de totalidad}

Por muchos años en los textos y las academias que enseñan Economía, su objeto de estudio ha sido definido como: el estudio de las causas del bienestar material de los hombres; como la ciencia que estudia la conducta humana; como una relación entre fines y medios limitados; en definitiva como la asignación eficiente de recursos escasos. Esta definición tiene entre sus defectos, el hecho de que diluye su objeto, o lo hace extensivo, quizás sin pretenderlo, hasta las ciencias naturales o algunas otras ciencias sociales, que no abarcan el objeto de estudio de las ciencias económicas.

Sin embargo, y emparentada con la definición anterior, el concepto más aceptado y divulgado a pesar de los diferentes matices, es el de considerar la Economía y la Teoría Económica, como el estudio del comportamiento humano; es decir, la manera como los hombres deciden usar los recursos eficientemente, en tanto tiene infinitas necesidades que satisfacer y medios limitados para lograrlo. Estas autoras han abordado en otros artículos la no neutrali-

Argum., Vitória, v. 10, n. 2, p. 43-55, maio./ago. 2018. 
dad del objeto de estudio de la Ciencia Económica como Ciencia Social, y cómo este ha sido secuestrado por la economía convencional, reduciéndolo y simplificándolo a la administración eficiente de recursos escasos.

En esta ocasión, la alusión al objeto y al método solo tiene como función expositiva insistir una vez más en que no hay método sin objeto, y que la discusión del método de demarcación científica para estudiar la realidad, tiene que explicitar el objeto de estudio del conocimiento; porque su definición es parte importante del posicionamiento entre conocimiento, ciencia y axiología. Objeto y método constituyen una unidad de totalidad.

Para Marx, “[...] en el análisis de las formas económicas de nada sirven el microscopio ni los reactivos químicos. El único medio de que disponemos, en este terreno es la capacidad de abstracción" (MARX, 1973, p. IX). En este punto lo importante no es señalar la abstracción como una necesidad científica y capacidad humana, sino saber cómo y de qué debe abstraerse el investigador en el proceso de búsqueda de la verdad, aun con la conciencia de que ésta es siempre relativa.

En Marx se despliega una total comprensión dialéctico-estructuralista del mundo económico real, lo que se puede comprobar en El Capital, obra en la que está plasmada su lógica de pensamiento y su método de investigación.

\begin{abstract}
Marx no opera, a la manera hegeliana "deduciendo" una categoría a partir de otra. Pone al descubierto las funciones de un elemento en el seno de una estructura, o de una estructura en el seno de un sistema, y explica el orden de esas funciones [...] Por consiguiente, el objeto de la teoría económica es descubrir dichas funciones y su orden en tal o cual estructura, y mediante ello definir las categorías de la economía política y articularlas entre sí en una especie de génesis lógica ideal (GODELIER, 1967, p. 77).
\end{abstract}

De lo que se trata entonces, es de tomar el objeto como un todo -por supuesto que en el campo de las delimitaciones del objeto, también es necesario la capacidad de abstracción del sujeto cognoscente- asumiéndolo en su dinámica estructural y contradictoria. Buscando penetrar en cada una de las partes que conforman la estructura, para poder establecer las características esenciales de cada parte, su lugar y papel dentro de la totalidad; así como, intentado analizar las múltiples relaciones causales y/o funcionales entre cada una de esas partes, para luego sintetizar -sobre la base de la determinación de lo típico, lo dominante- lo esencial del fenómeno. Ese camino ascensional, ese proceder ideal, tiene como instrumento básico precisamente la capacidad humana de abstracción científica. Solo a través de ese proceder, se puede llegar a lo concreto pensado, al conocimiento teórico de la realidad social, de la realidad económica. "Lo concreto es concreto, ya que constituye la síntesis de numerosas determinaciones, o sea la unidad de la diversidad. Para el pensamiento constituye un proceso de síntesis y un resultado, no un punto de partida” (GODELIER, 1967, p. 77).

Marx se caracteriza por el uso del método del materialismo histórico dialéctico en sus estudios de Economía. Este nuevo método fue elaborado sobre la base del análisis crítico del proceder científico que le precedió, resulta una superación dialéctica de los métodos abstracto-deductivo (utilizado por ejemplo por David Ricardo) propio de la lógica formal de las ciencias exactas, y del inductivo-empírico característico de las ciencias naturales, el que a

Argum., Vitória, v. 10, n. 2, p. 43-55, maio./ago. 2018. 
diferencia del método abstracto-deductivo, asume la contrastación empírica como único criterio de cientificidad.

El método desarrollado por Marx, constituye una superación dialéctica de ambos métodos, porque la razón analítica es un momento de la razón dialéctica. Debe recordarse que Marx reconoció el valor científico del método analítico-abstracto empleado por David Ricardo, aun cuando señalara las debilidades científicas del mismo; justo es señalar además, que la posibilidad de que Marx pudiera elaborar el nuevo método, también estuvo condicionado por los desarrollos teórico-metodológicos alcanzados el pensamiento filosófico y económico anterior a él.

En la totalidad del objeto y el método marxista cobra gran importancia el papel de lo lógico y lo histórico. Marx reconoce el carácter primario del movimiento histórico real, su reflejo pasivo en el pensamiento se convierte en una tarea imposible, de ahí que para Marx el reflejo no es la copia pasiva y paralela a lo real; sino la forma ideal de expresión o la reproducción intelectual de la realidad. Por eso el análisis se desarrolla en dos pasos, el paso del desarrollo teórico o lógico y el paso del movimiento histórico real. El primero es derivado y forma parte del movimiento de la historia real de las conexiones básicas de la historia real. De ahí su no abstracción absoluta de la realidad histórica factual y el movimiento cognitivo pendular entre el desarrollo dialéctico abstracto y la concreta percepción de la realidad histórica.

En El Capital, el desarrollo de lo lógico, es la expresión de la comprensión de lo histórico. Las determinaciones abstractas, en cada plano de análisis de totalidad de la realidad, son el modo lógico de reflejar el proceso histórico; es decir, un reflejo sintetizado según leyes proporcionadas por el proceso histórico.

En ese contexto, Marx llega a la conclusión en el plano epistemológico, de que es preciso trascender la descripción de los hechos económicos realizada por la Economía Política que le antecedió, como una construcción abstracta y artificial que debe ser sometida al campo de la crítica. En El Capital el discurso de Marx posee de manera total su especificidad científica, como proyecto de revolución de un dominio científico constituido (La Economía Política) y al mismo tiempo designa a este proyecto como "crítica". Todo el análisis de la crítica del marxismo sintetiza su totalidad como unidad analítica de filosofía, economía política y comunismo como alternativa.

\subsection{2) Economía Política y Economía.}

La Economía Política surge necesariamente como ciencia, en un momento histórico donde se había acumulado un caudal de conocimientos humanos, necesarios para ser generalizados en función de un mayor y mejor entendimiento de las relaciones socioeconómicas entre los hombres, con derivaciones de tipo político. Y esto es así precisamente porque la Economía Política como ciencia social, orienta, sugiere, es y debe ser base teórica para el diseño de las políticas económicas de los Estados.

Posiblemente haya sido Antoine de Montchrétien (1615) quien utilizara por vez primera el concepto de Economía Política en su libro de 1615 Tratado de Economía Política, para referirse a la "Economía del Estado" en el sentido de la administración pública. También en 1755 Rousseau escribió un artículo sobre Economía Política en la famosa enciclopedia francesa,

Argum., Vitória, v. 10, n. 2, p. 43-55, maio./ago. 2018. 
que más que de economía, trataba de política. Pero es necesario apuntar que el sentido moderno del término "económico", lo desarrolla Francois Quesnay en su conocida obra Tabla Económica en la segunda mitad del siglo XVIII(QUESNAY, 1758). Por otra parte, el famoso economista inglés David Ricardo, nominó a su más conocida obra económica, Principios de Economía Política y Tributación (RICARDO, 1817). De igual forma, en 1848 aparece la expresión Economía Política en el libro de Sir John Stuart Mill, Principios de Economía Política (MILL, 1848).

Resulta, sin embargo, curioso, que un economista como Adam Smith (1776) no utilizara la expresión economía política en su obra de 1776 , no obstante por su contenido, la obra del gran economista inglés, está referida al objeto de la Economía en el mismo sentido que escribieron y publicaron obras económicas los demás economistas en aquella época (Economía Política). Por su parte, la obra cumbre de Carlos Marx El Capital (1867), recibió como subtítulo Critica de la Economía Política. En esta obra Marx desarrolló la verdadera dimensión científica de esta ciencia, a partir de todo el conocimiento acumulado hasta ese momento y por demás, condicionado por el desarrollo alcanzado por el capitalismo en el siglo XIX.

A fines del siglo XIX la expresión o definición de la ciencia como Economía Política, comenzó a ser sustituida por el de Economía. Este es el período histórico donde la transformación del capitalismo de libre competencia en imperialismo, condicionó el surgimiento de una corriente interpretativa subjetivista de las relaciones entre los hombres y el mundo económico real. Pero precisamente la misma sociedad que históricamente condicionó el surgimiento de la Economía Política como ciencia con las funciones y objeto antes definidos, condicionó las modificaciones en el desarrollo de la misma, desvirtuando su verdadero objeto, y de cierto modo restándole su contenido social e histórico. Se trata de la vieja discusión entre conocimiento, ciencia y axiología. Se trata del conocimiento comprensivo del proceso total, que no se limita a las partes fenoménicas de manera aislada; sino que asume el conjunto de relaciones que permite entender la esencia de una generalidad.

Fue un proceso contradictorio, la manera como se produjo progresivamente la sustitución de la Economía Política por la llamada Ciencia Económica. Lo cierto es que en el año 1879, el economista inglés Alfred Marshall y su esposa Mary Paley Marshall, publicaron La Economía de la Industria, obra en la que plantean la conveniencia [según ellos] de abandonar la expresión Economía Política; porque la palabra política parecía ser inadecuada, puesto que la misma refleja intereses políticos de grupos sociales en una nación y por lo tanto la ciencia perdía su carácter como tal. Esta idea Marshall la consolida en su obra de 1890 Principios de Economía, la que ha sido considerada por muchos autores, como el primer tratado moderno de Economía.

A partir de ese momento comienza desterrarse el término de Economía Política, y paralelamente el replanteo del objeto y, por ende, del método de análisis de la realidad. Se produce un viraje epistemológico en la ciencia económica asumiendo una determinación aparencial, lógica, formal y racional de la realidad. El "perfeccionamiento" y "refinamiento" de la Economía desde finales del siglo XIX se consolida a partir de la teoría Económica Neoclásica.

Su contraparte, la Economía Política marxista le interesa descubrir la naturaleza de las relaciones de producción; en virtud de qué leyes y regularidades cambian; así como, su lugar y

Argum., Vitória, v. 10, n. 2, p. 43-55, maio./ago. 2018. 
papel dentro del conjunto de relaciones sociales de un modo de producción determinado. A su vez, busca revelar el carácter y las relaciones esenciales de los sistemas socioeconómicos y sus contradicciones. En otras palabras, la Economía Política marxista se enfoca en el estudio de las relaciones sociales de producción como forma de desarrollo de fuerzas productivas.

En este sentido, la propuesta de Marx es integral, tratándose de una teoría científica para interpretar y transformar la realidad (como determinaciones de totalidad). Por ello es una teoría social, política, económica, etc. En su obra "El Capital" se encuentra su formulación más completa, pudiendo hallarse en ella también los fundamentos de todo el edificio teórico del paradigma marxista.

La Economía Política como ciencia constituye un total de procesos gnoseológicos interconectados que requieren ser descompuestos y estudiados en sus partes para poder comprenderla como totalidad. Solo con la colocación de estos conocimientos como interconexiones dialécticas y volviéndolos a colocar en el terreno en que fueron abstraídos, se podrá reconstruir el diálogo necesario entre paradigmas que va mucho más allá de disciplinas especializadas.

Todas las formas de objetividad en las que el mundo aparece en la sociedad capitalista ocultan en su carácter de categorías económicas, su esencia, apareciendo como cosas y relaciones entre cosas. La ciencia burguesa le concede una autonomía a las abstracciones que realiza en las ciencias particulares, a través de la separación entre los objetivos de la investigación y la especialización científica. De ahí la necesidad de considerar a todos los fenómenos, como fenómenos parciales y momentos del todo. Esta totalidad es captada como unidad del pensamiento y de la historia. Marx rechaza todo tipo de visión parcelada y verticalizada de la ciencia, enfocando a dichos objetos de la investigación como momentos dialécticos que necesariamente tiene que presentar cierto aislamiento por abstracción de determinados dominios de investigación; pero que de manera decisiva tiene que ser entendidos como un medio para el conocimiento del todo, o sea, hay que integrarlos en un criterio de conjunto que trascienda la visión de ciencia jurídica, económica, histórica, etc.

\section{LA TOTALIDAD DEL MARXISMO PARA EL ANÁLISIS DEL CAPITALISMO Y DEL SO- CIALISMO: EL DUPLO DESAFÍO DEL MARXISMO}

El paso del Capitalismo de Libre Competencia al Imperialismo implicó profundos cambios. Algunos de ellos se concretan en la penetración del capital en la agricultura; las condiciones y efectos del desarrollo desigual; las guerras imperialistas como parte importante de los mecanismos de acumulación y del reparto económico y territorial del mundo; cambios en el Estado capitalista para representar los intereses del capital financiero; cambios en las formas productivas que implicaba el monopolio como esencia del Imperialismo; la exportación de capitales; las nuevas expresiones de crisis capitalistas. Por otra parte, en estas mismas primeras décadas del siglo XX, el marxismo tuvo que interpretar las nuevas condiciones para la posibilidad de la revolución en países capitalistas subdesarrollados; y concretar la utopía revolucionaria fundamentada en la visión marxista del cambio social, en el comienzo de la teoría de la transformación social socialista. 
El avance del siglo XX fue testigo de más de un ajuste del patrón de acumulación imperialista. El paso de una regulación monopolista privada, a una regulación monopolista estatal como respuesta de la crisis del 29 al 33; el paso de la regulación monopolista estatal a una regulación estatal transnacionalizada desde finales de los años sesenta; consolidada e instalada en la última década de la centuria con el seudónimo de Globalización y con apellido de Neoliberal, extendida al siglo XXI. El capital financiero internacional (por su contenido y formas) es la personificación de la oligarquía del capital, que ajustó su patrón de acumulación a partir de una valorización con énfasis en la tasa de ganancia, hacia nueva forma con énfasis en la tasa de interés.

Lo anterior evidencia la profundas transformaciones de la lógica del capital imperialista, que han complejizado las formas de subvertirlo. Por ello es importante rescatar el enfoque de totalidad y su expresión en la lucha de clases.

Muy importante reflexionar sobre la utilización del marxismo como paradigma de ciencia en el enfoque de totalidad para el análisis contemporáneo de las diferentes formas, expresiones y contextos de luchas de clases. El enfoque de la lucha de clases presupone la existencia de segmentación social; ya sea a través de alguna definición de clases, grupos o estratos sociales. El marxismo toma como criterio de demarcación científica para las clases, las relaciones que se establecen en el proceso de creación de la riqueza social, a partir de las relaciones de propiedad sobre los medios de producción. Las clases sociales pautan las formas y el lugar que los individuos ocupan y pueden ocupar en los procesos de organización de la producción; no sólo para la creación de la riqueza, sino también para su distribución y redistribución social.

Las reglas del juego pautadas por las relaciones sociales de producción como forma de desarrollo de las fuerzas productivas desde la producción social, definen también el resto de los procesos de redistribución de lo creado; así como, las formas en que las personas participan en los desdoblamientos como productores, consumidores, propietarios y clases o grupo social. De lo anterior se derivan, consciente o inconscientemente, demandas, debates, exigencias sobre justicia social, igualdad, equidad o sus combinaciones. No dejan de presentarse en esta discusión las antecedencias y relaciones entre los procesos, las jerarquías de las posibles conquistas sociales; así como, sus formas expresión a través de organización política y de masas.

Consideramos oportuno abordar acá la propuesta de totalidad del marxismo para el tema de la lucha de clases contemporánea por varios aspectos relevantes:

$\checkmark$ El desarrollo imperialista del capital ha cambiado de manera significativa las formas en las que permite participar a los individuos en los procesos de producción y valorización del capital.

$\checkmark$ La composición de la clase trabajadora ha cambiado. Ya no estamos en presencia de la clase trabajadora estudiada por Marx, y por tanto tampoco de su forma tradicional de organización social y política. El capital financiero imperialista trasnacionalizado ha fragmentado la visión de la clase trabajadora, y como consecuencia el propio concepto de clases sociales.

$\checkmark$ El capital financierizado y trasnacionalizado ha segmentado el "mercado de trabajo", y como consecuencia ha fragmentado y fracturado a la mercancía fuerza de trabajo;

Argum., Vitória, v. 10, n. 2, p. 43-55, maio./ago. 2018. 
así como sus formas de inserción en el "contrato social"; desdoblándola en manifestaciones como: el subcontratado, el autónomo, el trabajador a tiempo parcial, el emprendedor, el tercerizado, el "freelancer", la clase media ilusoria, el marginal, el "excluido", los desplazados, refugiados, emigrantes, "homeless", etc. Lo anterior ha recompuesto el contemporáneo ejército de reserva, como consecuencia de las contradicciones imperialista de la lógica del capital.

$\checkmark$ Las formas de superpoblación relativa del imperialismo actual, evidencian más que nunca que no solo sobran seres humanos para el mundo del trabajo, sino para la sociedad capitalista. El capital puede prescindir de parte de la sociedad, y para ello explora constantemente nuevas formas de exterminio.

$\checkmark$ Ha fragmentado la lucha de clases sustituyéndola y parcelándola como la lucha del campesino, del trabajador, de la ama de casa , del negro, del indio , etc.; y como consecuencia desactivado las formas tradicionales de organización social y política; así como, de conciencia social para enfrentar al capital imperialista

$\checkmark$ Ha fragmentado al sujeto portador de la transformación social, y ha reducido a formas concretas que excluyen a partes cada vez mayores de la población mundial.

$\checkmark$ En consecuencia esta fragmentación se traduce en posturas, proyectos societarios y objetivos diferentes. Se expresan en posturas de resistencias, reformismos, conservadurismos, conciliación; en proyectos de vías capitalistas de desarrollo, tercera vía, postcapitalismo, u otras propuestas más heterodoxas; así como, en objetivos que se enfocan indistintamente en la equidad, la igualdad, la justicia social, los derechos humanos, la libertad individual, etc.

La relevancia de no naturalizar la fragmentación de la sociedad y la lucha de clases de en los marcos del capitalismo imperialista contemporáneo implica un doble desafío del marxismo, por una parte, es asimilar críticamente los cambios de la lucha de clases para poder entender las formas concretas, en teoría y en práctica, en las que se puede articular para el cambio social. Por otra parte, es un gran desafío, una vez comenzada la transformación social, cómo hacer ruptura y superación de la estructura de clases heredada, de forma que no entre en contradicción con la construcción del hombre nuevo en el tiempo histórico monumental del imaginario socialista.

\section{CONSIDERACIONES FINALES}

En el bicentenario del natalicio de KarlMarx, a 135 años de de su muerte, a 151 años de la primera publicación de el capital y a más de 100 años de la primera experiencia de socialismo, el marxismo continua con vigencia como paradigma de ciencia para pensar la sociedad.

La cuestión es preguntarse si es posible esclarecer los problemas nuevos del orden capitalista a través de la lente del marxismo. La respuesta es positiva , siempre que se comparta que la propuesta de Marx contiene una matriz teórica metodológica y un paradigma para subvertir la realidad.

El presente siglo hereda la deuda social acumulada bajo la etiquetas diferentes generaciones de "Objetivos de Desarrollo", imposibles de cumplir en la medida que continúe avanzando el capitalismo imperialista como forma particular de creación de riqueza a través de la lógica de acumulación del capital; que en su desarrollo imperialista, va fundiendo el aparato estatal

Argum., Vitória, v. 10, n. 2, p. 43-55, maio./ago. 2018. 
y todas sus determinaciones al capital como relación social global de acumulación y una relación global de explotación, expropiación, enajenación y alienación.

En las ciencias sociales, el análisis y reflejo del objeto de estudio, supone necesariamente la abstracción. La realidad misma no está parcelada; es el investigador quien, mediante la abstracción como proceso del pensamiento, la subdivide, la separa para su mejor estudio y comprensión. El rescate de la totalidad desde el paradigma marxista implica también un enfoque integrado desde todas las ciencias que piensa la sociedad para transformarla, como ruptura y superación de la lógica del capital.

La totalidad es un fundamento transversal del paradigma marxista de ciencia. Trata del conocimiento comprensivo del proceso en su conjunto, que no se limita a las partes fenoménicas de manera aislada; sino que asume el conjunto de relaciones que permiten entender la esencia de una generalidad y relaciones causales que lo hacen universal. A pesar que la totalidad significa integrar los fundamentos y sus partes, es muy contradictorio observar la desfragmentación que sufre el marxismo desde otros paradigmas y desde sus propios seguidores.

El marxismo como paradigma de ciencia y sus principales fundamentos, son una propuesta para pensar la sociedad a través de un método. El método implica una ruptura epistemológica por basarse en la crítica para la interpretación esencial de la realidad; pero no como ejercicio teórico, sino como búsqueda de causas con un enfoque de totalidad, que exprese la articulación entre conocimiento, ciencia y axiología.

El paradigma científico iniciado por Marx en el siglo XIX, tuvo como objetivo declarado descubrir la ley económica fundamental de la acumulación capitalista en el estudio de la sociedad burguesa; para demostrar las relaciones de explotación y enajenación del hombre; así como, sus tendencias para subvertir el orden burgués establecido por la minoría, por otro con justicia social para la mayoría. El marxismo del siglo XX, en sus primeras décadas, tuvo que enfrentar el reto de desarrollarse capturando cambios cualitativos importantes de la sociedad capitalista contemporánea así como los cambios en la estructura social que lo acompaña. Colocar el fundamento marxista de totalidad en las luchas de clases es una necesidad para no fragmentar los procesos de transformación social entre sujetos, objetivos e imaginario de sociedad. Con ello se evita fracturar la justicia social como anhelo necesario posible entre la necesidad y el cómo hacer el cambio social.

El marxismo de inicios del siglo XX se enfrentó por tanto a un doble desafío: interpretar los cambios del capitalismo imperialista para subvertirlo; e interpretar las condiciones del avance de la transformación social socialista. Tuvo entonces una doble y compleja tarea en teoría y en práctica; la de continuar explicando la necesidad de cambio social del capitalismo imperialista, y paralelamente, interpretar y proponer el proceso del cómo hacer el cambio social que implicaba la transformación hacia el imaginario socialista. Al marxismo del siglo XXI se le agrega un tercer desafío, es el de un capitalismo imperialista regresivo, contrarrevolucionario; en donde a los problemas de la acumulación del capital imperialista, se le añaden contradicciones globales sociales, políticas, ambientales, destrucción de fuerzas productivas; etc. En resumidas, se trata de una crisis estructural y sistémica, como reflejo de la agudización de la crisis civilizatoria de la lógica del capital .

Argum., Vitória, v. 10, n. 2, p. 43-55, maio./ago. 2018. 
No se trata de volver al marxismo cuando el capitalismo está en crisis o negarlo cuando el socialismo no avanza como lo deseado. El marxismo contiene el desarrollo continuo de la crítica al capitalismo y la crítica de la nueva sociedad en su análisis de totalidad. El marxismo no es solo la crítica a la sociedad capitalista, sino que también es un proyecto de nueva sociedad y una interpretación de la evolución histórica, política y social; el marxismo es una utopía revolucionaria y científica, es una propuesta de futuro.

\section{REFERENCIAS}

GODELIER, M. Sistema, estructura y contradicción en El Capital de Marx. Pensamiento Crítico, La Habana, n. 11, p. 62-98, dic. 1967.

MARSHALL, A. Principles ofeconomics, great mind series. London: Macmillan and Co., Ltd, 1890.

MARSHALL, A.; MARSHALL, M. P. The economics of industry. London: Macmillam and Co., Ltd., 1879. Disponível em: <http://www.library.fa.ru/files/Marshall-economics.pdf>. Acesso em: 18 abr. 2018.

MARX, K. Prólogo a la Primera Edición. In: MARX, K. El Capital: crítica de la Economía Política. La Habana: ed. Ciencias Sociales, 1973 (1867).

MARX, K. Contribuición a la crítica de la Economía Política. La Habana: Editorial Progreso, 1989 (1859). Disponível em:

<https://pensaryhacer.files.wordpress.com/2008/o6/contribucion_a_la_critica_de_la_econo mia_politica.pdf $>$. Acesso em: abr. 2018.

MILL, J. Stuart. Principles of political economy. London: West Strand, 1848.

MONTCHRESTIEN, A. de. Tratado de Economía Política. Francia: [s.n.], 1615.

QUESNAY, F. Tableau economique. Francia: [s.n.], 1758.

RICARDO, D. Principios de Economía Política y Tributación. [s. 1.], 1817.

SMITH, A. An inquiry into the nature and causes of the wealth of nations. London: W. Strahan \& T. Cadell, 1776.

Olga PÉREZ SOTO trabajó en la concepción, delineamiento, redacción, revisión y aprobación de la versión del artículo a ser publicada.

Doctora en Economía Internacional por la Universidad de Barcelona. Profesora Titular de la Universidad de La Habana, Cuba.

Arelys ESQUENAZI BORREGO trabajó en la concepción, delineamiento, redacción y revisión del artículo.

Master en Economía por la Universidad de La Habana, Cuba. Doctoranda en el Programa de Pos-graduación en Política Social en laUniversidad Federal de Espírito Santo, Vitória-ES, (UFES)

Argum., Vitória, v. 10, n. 2, p. 43-55, maio./ago. 2018. 